\title{
The Study on Selection of human Model for Controllability Evaluation According to Working Postures
}

\author{
Dohoon Kim ${ }^{1}$, Sungjoon Park ${ }^{2}$, Youngjae Lim ${ }^{1}$, Eui S. Jung \\ ${ }^{1}$ Department of Industrial and Management Engineering, Korea University, Seoul, 136-701 \\ ${ }^{2}$ Department of Industrial and Management Engineering, Namseoul University, Cheonan, 330-707
}

\begin{abstract}
Objective: The purpose of this study was to suggest appropriate human model for ergonomic evaluation considering working postures on 3D space. Background: Traditionally extreme design rules have been widely utilized at the stage of designing products. Body size of 5th percentile and 95th percentile in stature has been generally selected for controllability and clearance evaluation, respectively. However, these rules had limitations in reflecting working posture in ergonomic evaluation. Method: In order to define working posture on 3D space, not only sagittal plane but also lateral plane was considered. Kinematic linkage body model was utilized for representation of working posture. By utilizing the anthropometric data of 2,836 South Korean male populations, the point cloud for end points of linkage models was derived. The individuals who were lacking in certain controllability were selected as human models for the evaluation. Result: In case of standing posture it was found that conventional approach is proper for all controllability evaluations. Contrary to standing posture, tall people had less controllability on control location below shoulder point in sitting posture. Conclusion: From the derived proper range on controllability, ergonomic evaluation rule was suggested according to working posture especially in standing and sitting. Application: The results of the study are expected to aid in selection of appropriate human model for ergonomic evaluation and to improve the usability of products and work space.
\end{abstract}

Keywords: Controllability, Human model, Working posture

\section{Introduction}

제품에 있어서 소비자의 욕구를 충족시키기 위해서 기능 뿐만 아니라 디자인요소도 고려해야 할 중요한 요소이다 (Lee et al., 2003). 하지만 최근에는 제품의 품질, 사용성, 만족도에 대한 고객의 요구도가 커지기 때문에 이를 활용한 연구가 체계적으로 요구되고 있다(Lim et al., 2010).

사용자의 신체치수 및 특성을 고려한 설계를 일컬어 물리 적 인터페이스(Physical User Interface: PUI)라 총칭하 며, 이는 인간공학적 설계에서 중요한 고려요소 중 하나이다
(Lee et al., 2003). 최근에는 GUI(Graphic User Interface), AUI(Auditory User Interface), PUI에 대한 연구가 인간 공학 분야 전반에 걸쳐 활발히 진행중이며, 소비자의 감성, 인지요소뿐 아니라 신체적인 크기 및 특징을 고려한 PUI에 대한 연구가 추후에도 중요해지고 있는 실정이다.

이러한 연구들이 늘어나면서 사용성을 평가한다는 것은 단순히 제품의 성능만을 고려하는 것이 아니라 사용자의 신 체적 조건, 환경까지 포함되어 있는 제품개발프로세스와 같 은 체계적인 접근방법이 요구된다(Jared et al., 1997). 따라 서 제품 설계 시 사용자의 신체지수를 측정하고 인체에 적합 한 설계가 이루어지도록 활발한 연구가 요구된다.

Corresponding Author: Eui S. Jung. Department of Industrial and Management Engineering, Korea University, Seoul, $136-701$. Phone: +82-2-3290-3391, E-mail: ejung@korea.ac.kr Copyright@2012 by Ergonomics Society of Korea(pISSN:1229-1684 eISSN:2093-8462 http://www.esk.or.kr). All right reserved. (c) This is an open-access article distributed under the terms of the Creative Commons Attribution Non-Commercial License(http://creativecommons.org/licenses/by-nc/3.0/), which permits unrestricted non-commercial use, distribution, and reproduction in any medium, provided the original work is properly cited. 
대표적인 예로 차량을 운전하거나 원자력 발전소에서의 조종장치를 제어하는 작업자의 경우, 사용자의 편의성과 안 전성이 중요시 되고 있으며, 이를 위해 작업환경 및 제품을 사용하는 사용자 개개인의 신체 크기 및 특징 그리고 신체 비례에 따른 인체측정변수의 변동요인을 반영해야 인체모델 을 개발하여 제품과 환경에 따라 인체가 갖는 데이터를 확보 할 필요가 있다. 또한 자동차 개발 시 사용자 중심의 운전자 를 위한 평가용 인체모델을 개발하여 조작, 시인 및 안락성 등 다양한 항목에 걸쳐 사용성을 평가하는 지표를 개발한 연 구도 있다(Eynard et al., 2000; Yang et al., 2007).

자동차는 운전자에 의해 조작되고 제어되기 때문에 신장 과 같은 인체변수가 고려된 신장별 인체모형의 범위를 고려 하여 설계되어야 한다. 하지만 사람마다 인체측정수치 및 자 료가 다르기 때문에 이러한 것들을 모두 적용시키기에는 현 실적인 제약이 따른다. 또한 소수의 대표 평가용 인체모델을 활용하는 편이 좀 더 제품 설계 및 개발을 위해 효율적이고 유용한 방법 중 하나이다(Badler et al., 2005).

현재 산업체에서는 생산하는 제품은 신장을 기준으로 조 작성에는 5th Percentile 적용하고 여유공간에는 95th Percentile에 해당하는 인체모델을 일반적으로 적용하고 있 다. 예를 들어 자동차의 Console Box 높이를 설계함에 있어 Gear-shift Lever 조작에 따른 운전자의 팔꿈치 이동 궤적 (Reach Trajectory)을 분석한 결과, 5th Percentile 또는 95th Percentile 의 인체모델보다 50th Percentile 인체모 델이 Console Box 높이 결정의 극단치 체형임을 알 수 있 었다(Park., 2009). 따라서 기존 연구에서 활용된 신장 위주 의 단순변수로 설계에 반영하여 인체모델을 생성하기 보다 3 차원 작업자세별 평가용 인체모델을 활용하고 신장별 인체 모델의 분포를 파악해서 보다 체계적인 인간공학적 설계가 필요하다.

\section{Method}

\subsection{Literature review}

기존 연구에서는 Kinematic Linkage Body Model을 생성 하여 인접한 지체들 사이의 관절각도를 정의하였다. 다음으 로 Size Korea(2004) 사업을 통하여 측정된 인체측정데이 터를 생성된 Linkage Model에 적용하여 적합한 변수로의 변환을 위한 Link Length 도출 과정이 진행되었다. 그에 따 라 측정 대상의 모든 인체치수에 대해 평가치를 개발하였고, 평가치 계산을 위해 정략적인 수식을 정의하였다. 평가치 계 산 수식은 인체의 관절좌표 및 앞선 단계에서 도출된 Link Length들의 조합으로 이루어 졌다. 따라서 자세에 따른
Body Link 조합에 의하여 손끝점 등 평가용 끝점(End Point)이 결정되며 이를 통해 2차원 좌표상에서 파악할 수 있는 사용성별 군집산포도(Point Cloud) 분포를 제시하여 집단 내에서 상대적으로 조작 능력이 열세인 그룹에 속하는 후보를 선별하는 인체모델에 대한 사용성별 인체모델을 제 시하였다(Lim et al., 2010).

또한 자동차 인간공학 분야에서 평가용 인체모델의 효율 성을 강조해 왔다. 예를 들어 시트를 조절하거나 Steering Wheel을 잡는 등의 운전자의 실제 Motion과 유사한 자세를 취함으로써 예상 가능한 사용 시나리오를 구현할 수 있다 (Julian Faraway et al., 2007). 따라서 인체모델은 콘트롤 조작 시 Reach나 Line of sight에 관한 문제를 평가하는데 유용하다(Chaffin., 2005).

\subsection{Research procedure}

기존 연구의 한계를 극복하기 위해서 본 연구에서는 2 차 원 분석뿐 아니라, 3 차원 평가가 가능한 측방 조작성을 추가 하여 확장된 연구를 진행하였다. 또한 작업자세(입식, 좌식) 별 신장 위주의 사용성 평가모델에 대한 평가 기준을 알아보 고자 하였다.

남자 성인 2,836명 중의 손을 뻗었을 때의 손끝점의 위 치가 조정장치에 닿지 않는 비율을 분석하기 위해 상방 및 측방에서의 실측 촬영을 통한 각도값을 추출하고 각 점 $(\mathrm{X}, \mathrm{Y}$, Z)에서의 좌표값에 대한 3차원 작업자세별 조작성 수용범위 및 손끝점 좌표값 추출을 통해 군집산포도(Point Cloud) 분포를 제시하였다. 그리고 이를 통해 (입식, 좌식) 작업자세 중에 하위 $20 \%$ 즉 6 개의 조작성 유형에 따라 조작이 힘든 인체모델을 찾아 신장별 유형을 파악해 보았다.

\subsection{D linkage body models with anthropometric variables}

실제 작업자세별 사용성 평가를 위해 사용자의 3 차원 공 간에서의 모습을 Kinematic Linkage Body Model로 구현하 였다(Park., 2006; Vogt et al., 2005). 이 Linkage Model 은 11 개의 지체들과 6 개의 관절각으로 구성하였다. 작업자 세를 정의하기 위하여 실제로 작업 중 자세(입식, 좌식) 값들 을 Linkage Model에 적용하였다. 사용자가 상황에 따라 관 절각도가 변화하게 되면 사용자의 손끝점이 도출되게 된다. 여기에 3 차원 상에서의 엉덩이 및 어깨 넓이를 고려하여 기 존 2 차원 사용성 평가 시 전방, 상방, 하방뿐만 아니라 3 차 원으로 확대하여 측방 조작까지 가능하도록 본 연구에서 실 시하였다.

Size Korea 인체측정 사업의 직접측정데이터를 기반으로 
하여 성별 및 연령에 따른 한국인의 다양한 인체 데이터베이 스를 활용하였다. 이 데이터베이스의 인체측정변수를 활용한 Link Length를 도출하였다. 본 연구에서의 Link Length의 기준은 기존의 연구를 준용하여 적용하였다(Park., 2009).

기존 연구의 한계를 극복하기 위해 3 차원으로서의 확장 L10, L11은 Figure 1과 같이 정의하였다. Top View 및 Sagittal View에서의 보여지는 어깨점과 엉덩이점의 Link Length를 추가하여 3차원상에 보여지는 Linkage Body Model의 기준을 완성하였다.

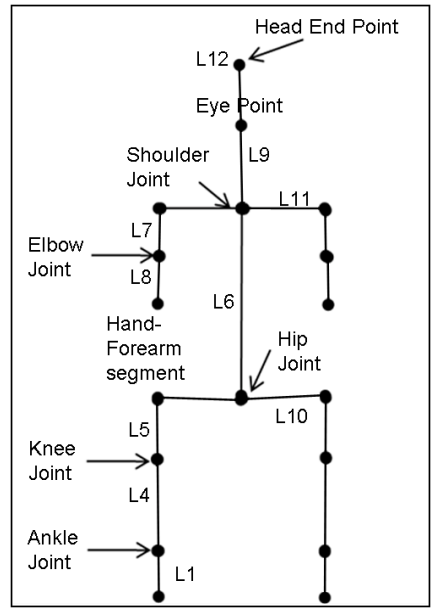

Figure 1. Kinematic linkage body model
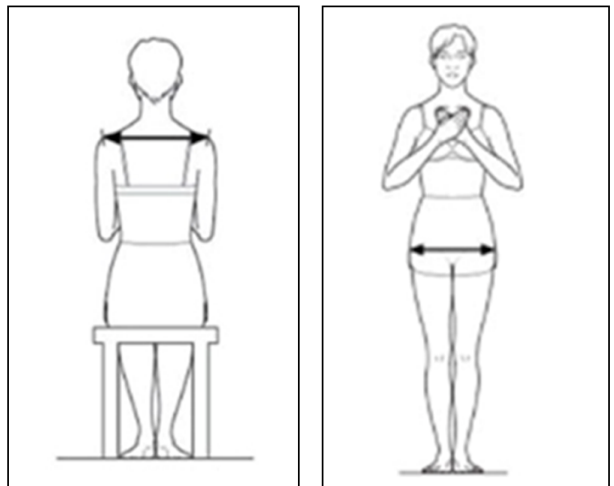

Figure 2. Definitions of biacromial breadth and hip width

\subsection{Six categories for controllability}

평가 전용 인체모델의 선정을 위해 우선 각 제품의 사용성 평가항목에 대하여 Size Korea 측정데이터 내에 인체들의 평가 순위를 계산하였다. 평가 순위를 계산하는 것은 사용 능력의 수용범위의 만족을 평가하기 위해서이다.
여기서 좌식 작업자세는 일반 사무작업 자세의 입식 작업 자세의 특성과 동일하게 나와서 교통 수단과 같은 사용자가 조작이 많이 발생하는 작업인 운전자세와 같은 대표자세를 좌식 작업자세로 정의하였고 입식 작업자세도 마찬가지로 사용자가 제품을 조작하는데 있어서 조작이 많이 발생하고 복잡한 조종장치를 사용하는데 있어서 불편함을 초래하는 원자력 발전소 작업 및 항해 시 조타실에서의 작업을 대표적 사례로 하여 적용하였다.

모든 분석은 Size Korea 측정데이터 중에서 남성 19세에 서부터 69 세까지 총 2,836명에 대해 평가자세를 계산하여 이에 따라 각 인체들에 대해 사용성을 평가하였고 이때 모든 인체모델은 실제 작업자세에서의 발꿈치가 지면에 닿는 부 분을 좌표계의 $(0,0,0)$ 으로 정의하여 분석하였다.

\subsubsection{Controllability evaluation for specific working posture in six views}

입식, 좌식 작업자세에서의 상방, 전방, 하방, 측방 조작성 평가는 사용자가 작업장에서 작업을 한다는 가정 하에 작업 자세에서 조종장치를 조작하기 위한 팔 동작자세를 반영하 여 조작성 여부를 평가한다는 가정이다. 인체를 발꿈치가 지 면에 닿는 부분을 좌표계의 $(0,0,0)$ 으로 정의하여 $\mathrm{X}, \mathrm{Y}, \mathrm{Z}$ 좌표계를 설정한다. 발, 하체, 그리고 Torso Link를 고정시 킨 상태에서 팔꿈치를 완전히 펴서 손끝을 사용하여 전방, 상방, 하방, 측방, 측상방, 측하방으로 반원을 그리면 그것이 인체의 3 차원 길이범위가 된다. 상방, 전방, 하방 조작성을 독립적으로 고려하기 위해서 반원으로 구해진 Reach 영역 을 다시 세 부분으로 나눈다.

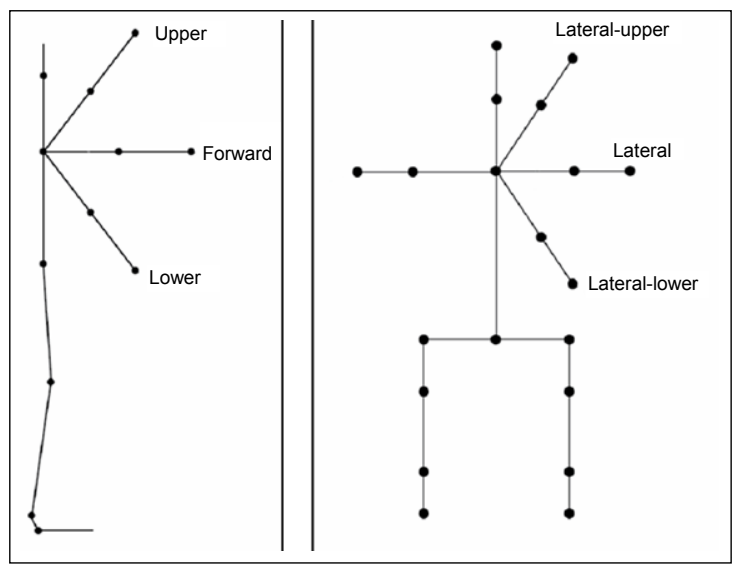

Figure 3. Definitions of controllability on 3D space

인체의 전방 조작성은 팔을 쭉 뻗은 자세에 해당하는 위 치이고, 상방 조작성은 팔을 전방방향으로 60 도 위로 뻗은 
자세의 위치, 하방 조작성은 팔을 전방방향으로 60 도 아래 로 뻗은 자세의 위치, 측방 조작성은 팔을 옆으로 45 도 뻗 은 자세의 위치, 측상방 조작성은 팔을 옆으로 45도, 위로 60 도 뻗은 자세의 위치, 측하방 조작성은 팔을 옆으로 45 도, 아래로 60도 뻗은 자세의 위치이다.

Table 1. Categories for controllability

\begin{tabular}{c|l}
\hline Forward & The position of arm reaching for forward \\
\hline Upper & $\begin{array}{l}\text { The position of arm reaching for forward and } \\
\text { upper } 60^{\circ}\end{array}$ \\
\hline Lower & $\begin{array}{l}\text { The position of arm reaching for forward and } \\
\text { lower } 60^{\circ}\end{array}$ \\
\hline Lateral & The position of arm reaching for lateral $45^{\circ}$ \\
\hline Lateral-upper & $\begin{array}{l}\text { The position of arm reaching for lateral } 45 \text { and } \\
\text { upper } 60^{\circ}\end{array}$ \\
\hline Lateral-lower & $\begin{array}{l}\text { The position of arm reaching for lateral } 45 \text { and } \\
\text { lower } 60^{\circ}\end{array}$ \\
\hline
\end{tabular}

\section{Results}

\subsection{The point cloud for end points of human linkage models according to working posture}

Body Linkage Model과 Size Korea의 측정데이터를 적 용해서 6 개의 조작성 평가 시 인체모델의 특징을 분석하여 신장에 따른 조작성을 검토하고자 하였다. 특히 전통적으로 사용되어 온 신장 중심을 토대로 평가하였고 열세 인체체형 (하위 $20 \%$ 인체)에서 신장별로 문제가 되는 인체변수를 도 출하였다.

Size Korea의 측정데이터를 기준으로 하여 19세부터 69 세까지의 성인 남성 2,836 명 중에서의 입식, 좌식 작업자세 인체별 손끝점을 도출하였다. 전방, 상방, 하방, 측방, 측상방,

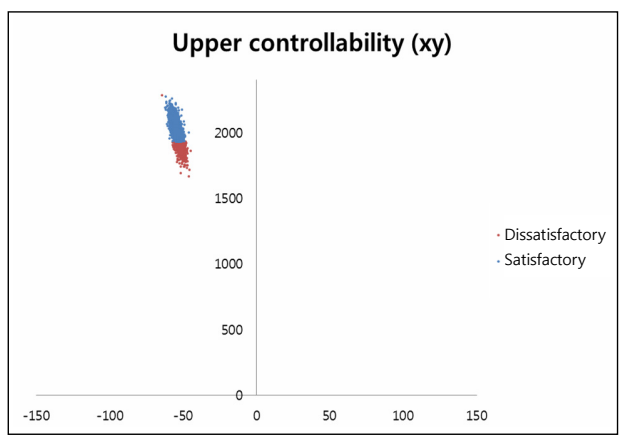

(a) Lateral-view

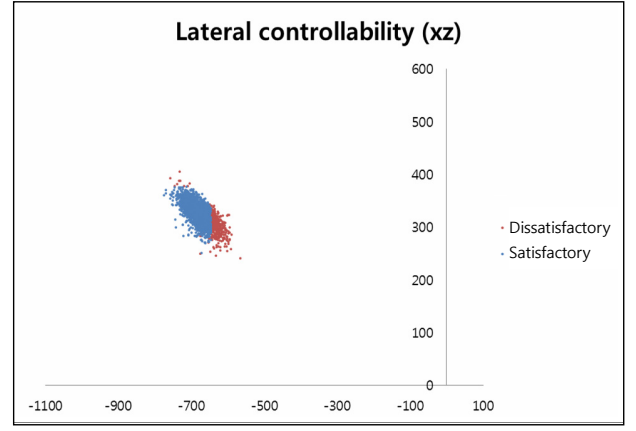

(b) Top-view

Figure 4. The point cloud of controllability according to standing posture

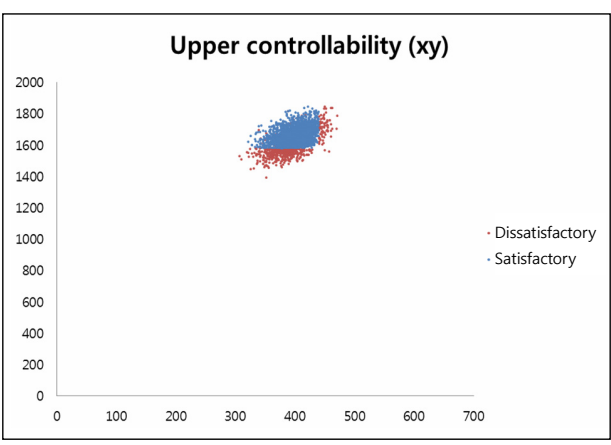

(a) Lateral-view

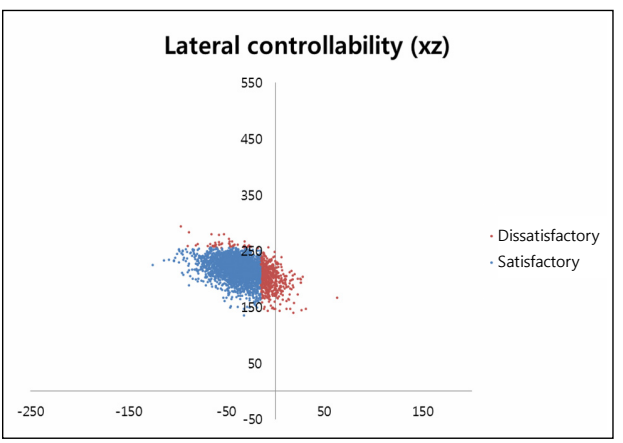

(b) Top-view

Figure 5. The point cloud of controllability according to sitting posture

측하방 조작성을 3 차원 좌표상에서 각각의 조작성을 고려하 여 도출된 군집산포도의 분포는 Figure 4,5 과 같다.

군집산포도 분포에서 진하게 표시된 좌표들은 측정 대상 자 중에서 조작성 능력이 열세인 인체체형 손끝점을 나타낸 다. 전방 조작성은 손을 앞으로 뻗었을 때 조작하는 기구들 이 닿기 어려운 공간. 즉, $\mathrm{X}$ 축이 몸통방향으로 오게 되는 인 
체모델의 $20 \%$ 가 열세 인체체형으로 선별하였고, 상하방 조 작성은 손을 위로나 아래로 뻗었을 때 X축이 몸통방향으로 $\mathrm{Y}$ 축이 낮거나 높은 인체모델의 $20 \%$ 를 조작성 열세 인체체 형으로 판단하였다. 또한 측방 조작성은 손을 옆으로 뻗었을 때 $\mathrm{X}, \mathrm{Z}$ 축으로의 조작하는 기구들이 몸통방향으로 위치하여 닿기 힘들고 $\mathrm{Y}$ 축이 낮거나 높은 인체모델의 $20 \%$ 를 조작성 열세 인체체형으로 선별하였다.

\subsection{The characteristics of human models with respect to stature on controllability}

여기서 작업자세별 신장별 분포는 4 가지의 범주(Size Korea의 측정 데이터를 기준으로 하여 19세부터 69세까지 의 성인 남성 2,836명을 신장 순으로 4 분위)로 나누어서 범 주를 정의 하였고 작업자세별 사용성 평가 기준의 인체모델 적용을 위해서 6 개의 조작성에 따른 열세그룹(인체모델)

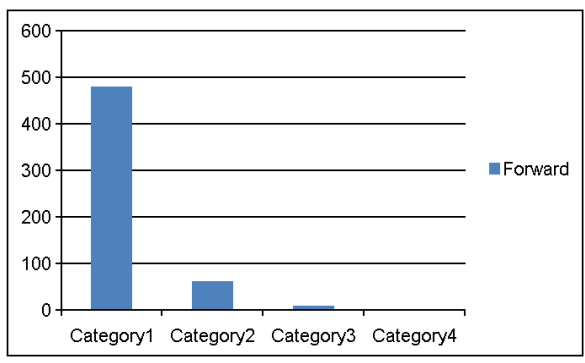

(a) Forward controllability $(p-v a l u e=0.000)$

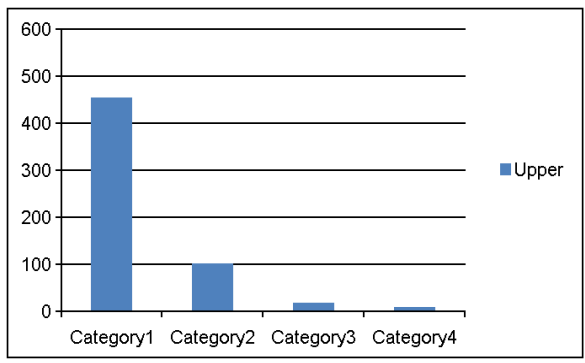

(b) Upper controllability $(p-$ value $=0.000)$

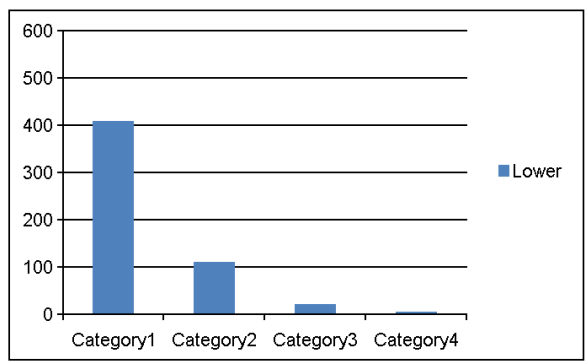

(c) Lower controllability $(p-$ value $=0.000)$

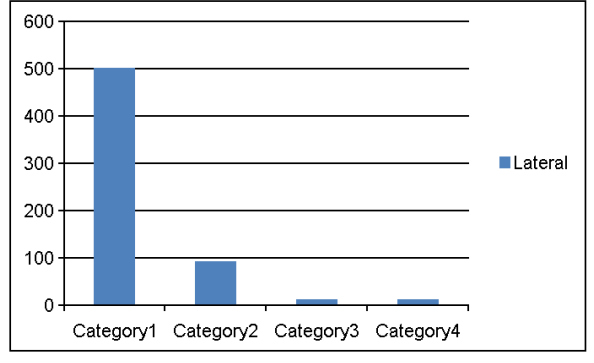

(d) Lateral controllability $(p-$ value $=0.000)$

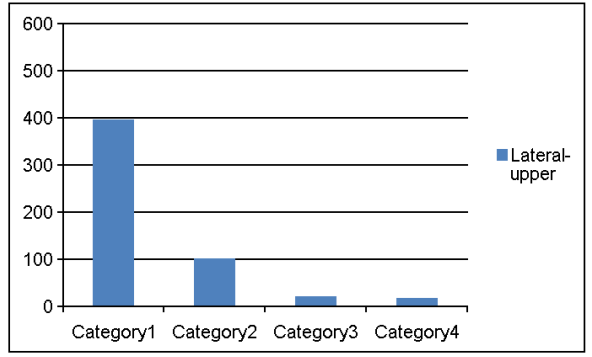

(e) Lateral-upper controllability $(p$-value $=0.000)$

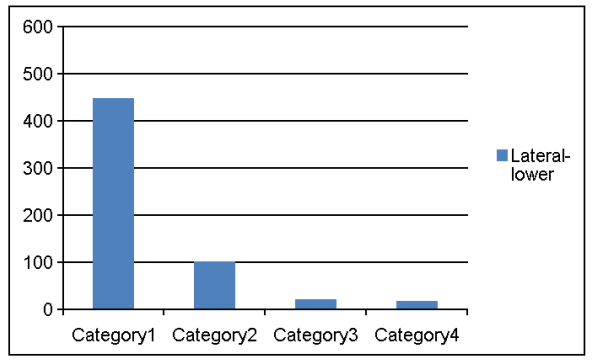

(f) Lateral-lower controllability $(p$-value $=0.000)$

Figure 6. The portion of inferior group according to stature (standing posture)

$20 \%$ 중에서 신장별 분포를 분석하고 신장과의 유의성을 여 부를 검정하기 위해 Chi-square 검정을 실시하였다.

입식 작업자세 열세그룹을 신장별로 분석한 결과 전체 조 작성에서 신장이 작을수록 조작기구들에 닿기 어렵다는 분 석이 나왔다. 이는 입식 작업자세에서는 기존에 제시한 바와

Table 2. The results of chi-square test in standing posture

\begin{tabular}{c|c|c|c}
\hline Category & Observation & Expectation & \multirow{1}{*}{} \\
\cline { 1 - 3 } 1 & 442 & 137.5 & \multirow{2}{*}{$p$-value $=0.000$} \\
\hline 2 & 100 & 137.5 & \\
\hline 3 & 18 & 137.5 & \\
\hline 4 & 10 & 137.5 & \\
\hline
\end{tabular}

$*$ : significance at $\alpha=0.05$ 
같이 표준체형의 사람, 또는 신장만을 기준으로 크고 작은 사람을 고려하여 설계하는 것이 옳다라는 결론과 동일하다. 그리고 신장별 분포의 유의성을 검정하기 위해 Chi-square 검정을 실시한 결과, 신장별 분포에서 모두에서 통계적으로 유의한 결과를 보였다.

앞에서 언급한 것처럼 좌식 작업자세는 교통 수단과 같은

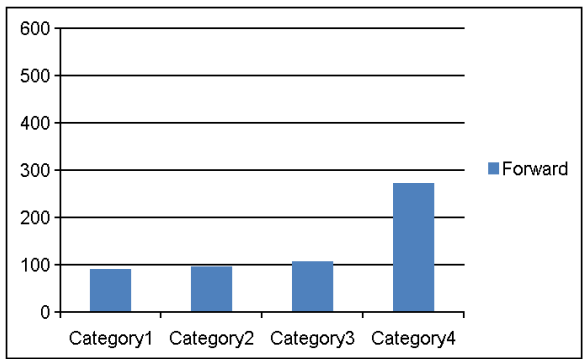

(a) Forward controllability $(p$-value $=0.000)$

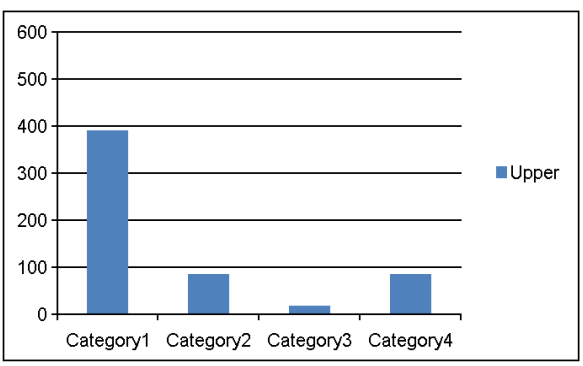

(b) Upper controllability $(p-$ value $=0.000)$

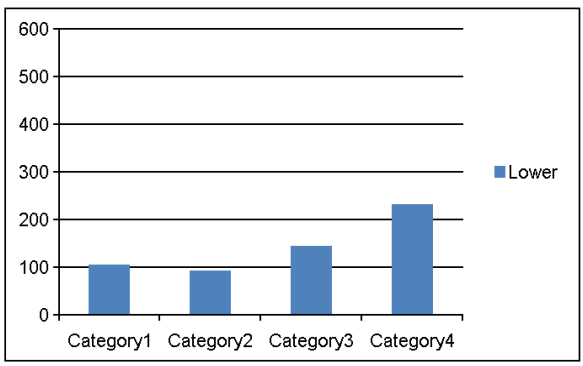

(c) Lower controllability $(p$-value $=0.000)$

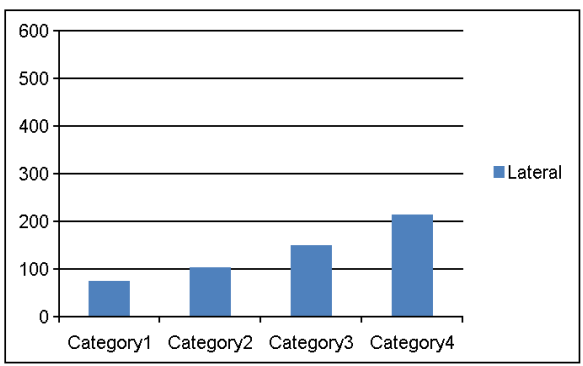

(d) Lateral controllability $(p-$ value $=0.000)$

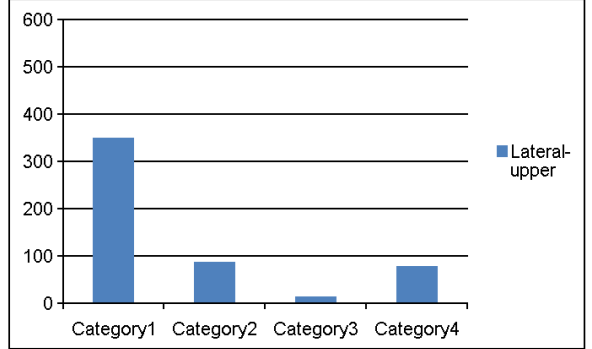

(e) Lateral-upper controllability $(p$-value $=0.000)$

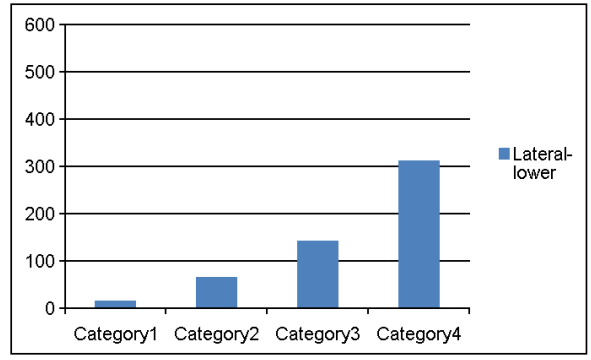

(f) Lateral- lower controllability $(p$-value $=0.000)$

Figure 7. The portion of inferior group according to stature (sitting posture)

사용자가 조작이 많이 발생하는 작업인 운전자세와 같은 자 세를 좌식 작업자세로 정의하였고 열세그룹을 신장별로 분 석한 결과, 상방, 측상방 조작성에서는 입식 작업자세와 같 은 신장이 작을수록 조작기구에 닿기 어렵다는 분석이 나왔 다. 하지만, 그 외의 조작성에서는 신장이 클수록 기구에 닿 기 어렵다는 입식 작업자세에서의 결과와 반대되는 결론이 도출되었다. 이는 좌식 작업자세에서는 전통적으로 조작성 평가에 사용되어 왔던 신장이 작은 사람 기준의 평가가 적합 하지 않음을 나타낸다.

즉 기존 연구에서는 분석되지 않았던 문제점들이 본 연구 에서 제시한 다양한 조작성 평가를 통하여 발견될 수 있었 으며, 이러한 분석 사례를 통해 단순히 기존 연구에서 주장 하였던 신장이 큰 사람 위주로 설계를 하는 것이 아니라 사 용자의 작업의 특성에 따라 작업자세가 달라 지게 되는 것

Table 3. The results of chi-square test in sitting posture

\begin{tabular}{|c|c|c|c|}
\hline Category & Observation & Expectation & \multirow{5}{*}{$p$-value $=0.000$} \\
\hline 1 & 19 & 137.5 & \\
\hline 2 & 56 & 137.5 & \\
\hline 3 & 146 & 137.5 & \\
\hline 4 & 316 & 137.5 & \\
\hline
\end{tabular}


을 고려하여 작업자세 및 조작성에 근거하여 인간공학적 설 계를 해야 한다. 마찬가지로 신장별 분포의 유의성 검정을 위해 Chi-square 검정을 실시한 결과, 신장별 분포 모두 통계적으로 유의한 차이를 보였다.

\section{Conclusions}

본 연구에서는 작업자세별 사용성 평가 기준이 인체모델 에 영향을 준다는 가정하에 본 연구를 실시하였다. 우선 사 용자의 작업 유형도에 따라 인체모델의 작업자세가 달라지 고 각각의 작업을 수행하는 것에 있어서 적합한 작업자세를 선정하고 그에 따른 사용성 평가 기준의 인체모델을 선정하 는 것이 작업공간 설계에 있어서 보다 효율적일 것이다. 기 존의 연구와 같이, 신장이 크고 작은 정도를 설계요소에 반 영하기에는 부족한 점이 존재하고 단순히 신장을 고려하여 조작성 및 사용성을 평가한다는 것은 한계가 존재할 수 있다. 즉, 조작성 평가는 작은 사람, 여유공간 평가는 큰 사람이라 는 획일적 기준을 탈피하여 작업자세에 따라 사람을 대상으 로 하는 조작성의 적합성을 평가해야 할 필요가 있다.

연구에서 나온 결과를 바탕으로 평가해 볼 때, 입식 작업 자세와 좌식 작업자세와 같이 작업자세가 다른 작업에서의 조작성의 차이가 발견되었다. 예를 들어 입식 작업자세의 경 우, 상방에서 짐을 꺼낼 경우와 전방 조작성과 관련된 자동 차의 도어 손잡이를 열 때도 기존에 키가 작은 사람을 기준 으로 설계가 이루어져야 한다. 또한 하방 조작성의 경우는 원자력 발전소의 기구들 중 하방에 위치한 조작기구를 조작 할 경우에도 키가 작은 사람 위주의 설계가 이루어 져야 한 다. 좌식 작업자세의 경우에 측방에 위치한 재떨이 등을 사 용하여야 할 경우, 키가 큰 사람을 대상으로 사용성에 대한 적합도 평가가 이루어져야 한다. 이와 같이, 입식과 좌식 작 업자세에 따라 조작성에서의 신장별 차이를 보이기 때문에 이를 고려하여 설계가 이루어져야 한다.
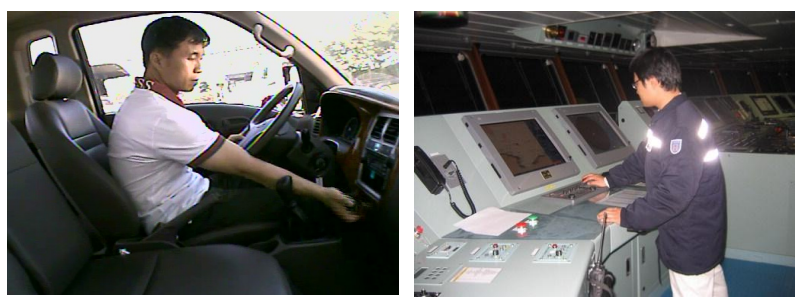

Figure 8. Working posture according to sitting and standing
작업의 특성에 따라 인체의 자세가 달라지고 사용자가 조 작을 하는 경우 각 작업에 적합한 신장이나 조작성 등을 선 별하여 주는 것이 합리적이다. 본 연구에서는 작업자세를 정 의하고 각각의 인체 길이를 바탕으로 조작성 열세에 해당하 는 후보 $20 \%$ 를 선정하였고 평가용 인체모델의 조작성에 따 른 신장과의 유의한 차이를 분석하였다. 본 연구의 결과에서 는 6 개의 조작성별 적절한 평가 인체모델을 제시하면서 제 품 조작성의 사용성 수용범위를 높일 수가 있었다. 6 개의 조 작성별로 결과가 다르게 나왔는데, 입식 작업자세에서는 전 부 키가 작은 사람 위주로 설계를 해야 하며, 좌식 작업자세 에서는 상방, 측상방 자세에서는 키가 작은 사람으로 그 외 에 작업자세에서는 키가 큰사람 위주로 설계를 해야 한다. 작업자세별 조작성 평가의 결과는 Figure 9 과 같다.

추후 연구에서는 작업자세 및 조작성 유형별로 신장 이외 의 인체변수 중 조작성 평가에 영향을 미치는 변수를 분석하 여 보다 적절한 조작성 평가용 인체모델을 선정할 수 있는 기준을 마련하는 연구가 필요할 것이다.

나아가 사용성 평가 인체 선정 과정에서의 평가 기준을 제 고하고 제품을 설계하거나 제품 설계자가 사용하는 프로그 램과 연동하여 제품의 상품성과 사용자의 적합성을 평가할 수 있으며, 산업화 현장에서의 작업공간 설계 시 초기 단계 에서의 시행착오를 줄이는데 기여할 것이다.

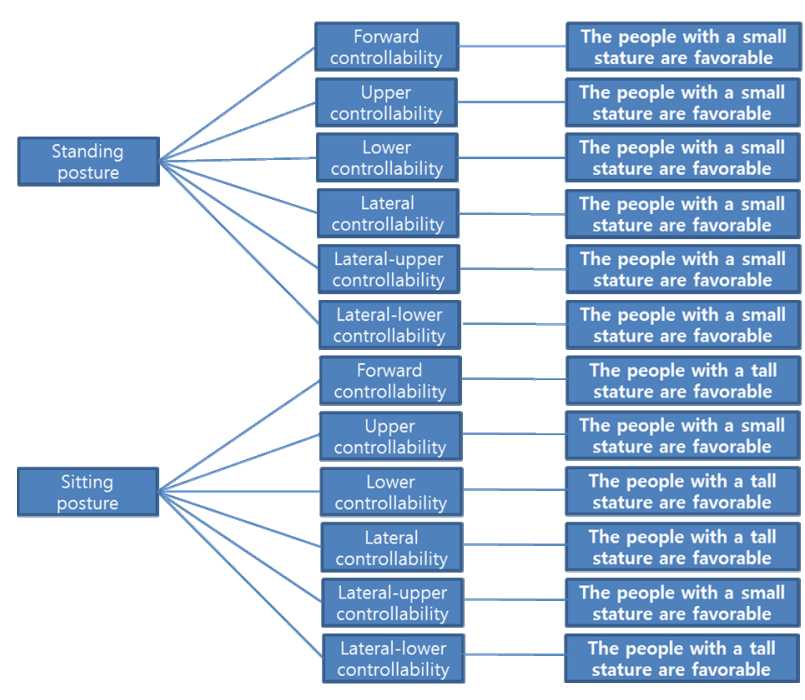

Figure 9. A set of human model according to working posture

\section{References}


K., New behavioral paradigms for virtual human models, $S A E$ Technical Paper, 114, 723-729, 2005.

Chaffin, D. B., Improving digital human modeling for proactive ergonomics in design, Ergonomics, 48(5), 478-491, 2005.

Eynard, E., Fubini, E., Masali, M., Cerrone, M. and Tarzia, A., Generation of virtual man models representative of different body proportion and application to ergonomic design of vehicles, Proceedings of the IEA2000/HFES2000 Congress, 489-492, 2000.

Jared M. Spool., Tara Scanlon and Carolyn Snyder, Product Usability: Survival Techniques, proceeding of CHI 97 conference on Human factors in computing systems, 154-155, 1997.

Julian, F., Statistics for Digital Human Motion Modeling in Ergonomics, Technometrics, 2007.

Lim, Y. J., Park, S. J., Park, W. J., Park, J. S., Jung, E. S. and Lim, I. S., Development Software to Select Boundary Manikins for Product Evaluation: Applied to an Automobile Case Ergonomics Society of Korea, 2010.

Lee, K. S., Yoo, H. C., Kwon, O. C. and Jung, M. C., "The development of process for extracting PUI design guideline", Ergonomics Society of Korea, 355-358, 2007.

Park, S. J., Estimation of Driver's Standard Postures by a Multivariate Analysis Method, Ergonomics Society of Korea, 25(1), 27-33, 2006.

Park, S. J., The development of Korean marginal human model for ergonomic product development, Korea Agency for Technology and standards, 2009

Park, J. H., Han, C. M. and Woo, C. W., "The study on framework of vehicle interior evaluation at usability test", Ergonomics Society of Korea, 2007.

Pheasant, S., Bodyspace: Anthropometry, ergonomics and eesign. London: Taylor \& Francis. 1988.

Vogt, C, Mergl, C. and Bubb, H., Interior Layout Design of Passenger Vehicles with RAMSIS, Human Factors and Ergonomics in Manufacturing, 15(2), 197-212, 2005.

\section{Author listings}

Dohoon Kim: keyboy4@korea.ac.kr

Highest degree: BS, Department of Electronic and Information, Daiichi University

Position title: MS candidate, Department of Industrial and Management Engineering, Korea University

Areas of interest: Product Development, Affective Engineering

Sungjoon Park: sjpark@nsu.ac.kr

Highest degree: PhD, Department of Industrial Engineering, POSTECH Position title: Professor, Department of Industrial and Management Engineering, Namseoul University

Areas of interest: Product Development and Design

Youngjae Lim: ergoim@korea.ac.kr

Highest degree: MS, Department of Industrial System and Information Engineering, Korea University

Position title: PhD candidate, Department of Industrial and Management Engineering, Korea University

Areas of interest: Product Development, Affective Engineering

Eui S. Jung: ejung@korea.ac.kr

Highest degree: PhD, Department of Industrial Engineering, Pennsylvania State University

Position title: Professor, Department of Industrial and Management Engineering, the University of Suwon

Areas of interest: Product Development, Affective Engineering, Human Factors and Ergonomics

Date Received : 2011-11-16

Date Revised : 2011-11-22

Date Accepted : 2011-12-15 